\title{
Non-Metastatic Gestational Trophoblastic Tumor
}

National Cancer Institute

\section{Source}

National Cancer Institute. Non-Metastatic Gestational Trophoblastic Tumor. NCI

Thesaurus. Code C9176.

Gestational trophoblastic tumor that is confined to the site in which it initially manifested. 